Chapter 1

\title{
The History of Paleontological Investigation in Western Abu Dhabi Emirate
}

Mark Beech ${ }^{1}$, Brian Kraatz ${ }^{2}$, and Faysal Bibi ${ }^{3}$

1. Historic Environment Department, Department of Culture and Tourism, Abu Dhabi, United Arab Emirates. email: mark.beech@dctabudhabi.ae

1. Western University of Health Sciences, Pomona, California, USA

2. Museum für Naturkunde, Leibniz Institute for Evolution and Biodiversity Science, Berlin, Germany

Running head: History of investigation 


\section{Introduction}

The story of the discovery of late Miocene fossils within the Baynunah geological formation in Abu Dhabi's western Al Dhafra region concerns a host of international paleontologists, many of whom have contributed to this volume, as well as the backing of their related scientific institutions. In particular, the first study of the Baynunah owes a lot to the late Peter Whybrow (1942-2004) and a co-editor of the present volume, the late Andrew Hill (1946-2015). The discovery of the majority of the important fossils described in this publication would have not happened without their personal contributions. From the early 1980s until today, the Abu Dhabi government has always been a supportive partner to this paleontological research and continues to document, research, and protect important fossil sites that are part of the late Miocene Baynunah Formation, as well as curate the important collection of fossil specimens resulting from this work. This present publication provides details of the latest comprehensive overview of the Baynunah fossils and updates the earlier volume, Fossil Vertebrates of Arabia (Whybrow and Hill, 1999). A large number of new fossil specimens were discovered during the newer field seasons of work carried out between 2003 and 2018. This has provided an opportunity to undertake major revisions and updates of some of the Baynunah fauna. Let us first consider, however, the history of previous research.

\section{Early Paleontological Work}

"...Climate appears to limit the range of many animals, though there is some reason to believe that in many cases it is not the climate itself so much as the change of vegetation consequent on climate which produces the effect... Where barriers have existed from a remote epoch, they will at first have kept back certain animals from coming in contact with each other; but when the assemblage of organisms on the two sides of the barrier have, after many ages, come to form a 
balanced organic whole, the destruction of the barrier may lead to a very partial intermingling of the peculiar forms of the two regions..." (Wallace 1876: 10 and 46).

When Wallace published his thoughts about the global interrelationship of the changing geosphere with the biosphere, the geography, fauna and geology of the Arabian interior was relatively unknown. Early publications alluded to the dispersal into Arabia of some present day African and Asian mammal faunas (Thomas 1894; Thomas 1900; Yerbury and Thomas 1895), but nothing much could be said about the dispersal of Tertiary continental faunas into or out of Arabia - or even of their origination there - as none had been discovered.

During the 1930's the search for oil began in Arabia and this helped to provide the first topographical and geological maps of the region. Natural historians also began to explore the fauna and flora within Arabia's diverse arid habitats. Although paleontological work had been carried out during the late $19^{\text {th }}$ century in the foothills of the Himalayas and in East Africa, where traces of Tertiary period mammals had been discovered, Arabia was a paleobiogeographical gap in our knowledge of Old World low-latitude continental Tertiary vertebrate faunas. Some clues concerning the presence of vertebrate fossils in Abu Dhabi began to be noted by oil company geologists. For example, in an unpublished survey of 1949, D.A. Holm and R. Layne reported "probable horse teeth and bones" at Jebel Dhanna. In that same survey they also visited Jebel Barakah and produced a geological section.

R.A. Bramkamp and L.F. Ramirez, geologists working with the Arabian-American Oil Company (ARAMCO) in the 1940s and 1950s, examined rocks in the Western Region of Abu Dhabi and thought that they were middle Miocene in age, about 14 Ma. They equated them with formations previously described in eastern Saudi Arabi, the marine Dam Formation, dated to 
between 19 and $16 \mathrm{Ma}$, and the overlying continental Hofuf Formation, estimated to be about 14 Ma.

Ken Glennie, now honorary Professor of Geology at Aberdeen University in Scotland, served after the second world war in Libya and Egypt, where he developed a love of deserts. In 1949 he left the army to study geology at the University of Edinburgh. His degree was followed by an M.Sc. funded by the oil company Shell. Following work in England, Scotland, Germany, Austria, New Zealand, the Canadian Arctic, and North America, he was asked by Shell to become their desert expert. This work took him to Libya followed by India, then to the Trucial States (now known as the United Arab Emirates (UAE) and Oman. This culminated in the publication of his book Desert Sedimentary Environments (Glennie, 1970), which is still a classic on the subject. During the late 1960s he spent two years leading a team undertaking geological mapping of the Oman mountains. This work investigated the relationship between the development of the fantastic mountain range with the foreland oilfields of the southwest. This study had far-reaching implications for understanding the tectonics of the Middle East. In 2005 Ken Glennie published The Desert of Southeast Arabia: Desert Environments and Sediments (Glennie 2005).

Ken Glennie had already published several formative articles, including an observation that there was 'dikakah' (plants and plant-root structures associated with aeolian sand) in Abu Dhabi's Western Region during fieldwork he carried out in 1965 (Glennie and Evamy 1968). It was recognized that the vertebrate-bearing fluvial sands and gravels of the late Miocene Baynunah Formation were the probable source of the moisture that permitted this plant growth and downward root penetration ('dikakah') into the dune sands. Glennie also mentioned the presence of proboscidean tooth remains from Jebel Barakah and believed the enclosing sediments to be dune sands and wadi conglomerates. 
A number of oil company geologists also remarked upon the presence of vertebrate fossils in Abu Dhabi's Western Region. Staff of the United States Geological Survey discovered a fossil site at Tarif (site T2, or TAR 2) in a section beside a road cut, with a partial skull of an antelope, Tragoportax cyrenaicus. There was also an anonymous report lodged in the Natural History Museum in London in 1975 concerning fossil remains discovered in Saudi Arabia (Anon 1975).

\section{Whybrow and Hill: 1979-1999}

The history of paleontological work in Al Dhafra (formerly known as Al Gharbia or the Western Region) has been summarized by Hill et al. (1999) and later by Hill et al. (2012) and Bibi et al. (2013). That history is provided here in more detail.

Systematic work on fossils in the Western Region of Abu Dhabi began with the involvement of the late Peter Whybrow from the Palaeontology Department at the Natural History Museum, London, and the late Andrew Hill, who was the J. Clayton Stephenson professor of Anthropology at Yale University, and a curator and head of the division of anthropology in the Yale Peabody Museum of Natural History. Before coming to Yale, Hill had held research positions at the National Museum of Kenya, the directorship at the International Louis Leakey Memorial Institute of African Prehistory in Nairobi, as well as a research fellowship at Harvard University.

Peter Whybrow first came to southeastern Arabia in 1979 to carry out fossil research in Qatar on behalf of what was then the British Museum (Natural History) and later became The Natural History Museum (NHM). During that visit, he made a one-day trip across the border into the Emirates, visiting Jebel Barakah, an outcrop on the coast west of Jebel Dhanna. There he found fossil remains of crocodiles and recognized the importance of the rock outcrops in the 
Western Region (Whybrow and McClure 1981; Madden et al. 1982; Whybrow 1984 1987, 1989; Whybrow and Bassiouni 1986; ). On another visit to Jebel Barakah in 1981, working in collaboration with the Geology Department of the Emirates University, he found more fossils, including teeth of primitive horses, which he dated to the late Miocene epoch, from 5 to $11 \mathrm{Ma}$.

In 1983-1984 an archeological survey of the coastal area of Abu Dhabi’s Western Region involving Walid Yasin Al-Tikriti of the former Abu Dhabi Department of Antiquities and Tourism - Al Ain, as well as a group of German archeologists led by Burkardt Vogt, discovered fossils at localities further east of Jebel Barakah (Vogt et al. 1983). Fossils found by this and all later expeditions were given the prefix AAM (for Al Ain Museum), later changed to AUH (the Abu Dhabi airport code). One of the important specimens discovered in the 1983-1984 survey was a hippo mandible - AUH 457 (Boisserie et al. 2017; Boisserie and Bibi, this volume). Some of these fossils were subsequently shown to the German archeologist and zooarcheologist HansPeter Uerpmann from the University of Tübingen, who was working in both the UAE and Oman. Realizing their great age, he subsequently recommended that they be shown to Andrew Hill. This resulted in an invitation from the former Department of Antiquities and Tourism in Al Ain for Andrew Hill to make a visit in 1984 to the United Arab Emirates to examine these fossils and to visit the sites.

After hearing about each other's work, Whybrow and Hill decided to come together to plan a joint program of research. Collaborative work began in 1986, and in 1989 and 1990 they worked in association with the former Department of Antiquities and Tourism in Al Ain, and then from 1991 onwards for a further five years the Whybrow (NHM) - Hill (Yale) expedition carried out further studies with sponsorship from the Abu Dhabi Company for Onshore Oil Operations (ADCO). 
This phase of investigations resulted in a number of publications (Gee 1989; Hill et al.1990; Whybrow et al. 1990, 1991, 1999; de Bruijn and Whybrow 1994; Whybrow and Hill 2002) and culminated in the First International Conference on the Fossil Vertebrates of Arabia, held under the sponsorship of the then Minister of Higher Education and Scientific Research, his excellency Sheikh Nahyan bin Mubarak Al Nahyan, with the support of ADCO at the Dhafra Beach Hotel at Jebel Dhanna in March 1995. Subsequently, these conference contributions appeared in the edited volume Fossil Vertebrates of Arabia (Whybrow and Hill 1999), which formed the most detailed description of the Baynunah fauna, geology, and regional context to date. More popular accounts of the work were also published (Whybrow et al. 1996, 1998, 2005; Whybrow 2003). As part of the public outreach of this research an exhibition on the work was

mounted at the Natural History Museum, London. A film was made to accompany this exhibition called Hot Fossils from Abu Dhabi - featuring and narrated by David Attenborough. Another film called Abu Dhabi: The Missing Link was also made in both English and Arabic for ADCO in 1991.

\section{Abu Dhabi Islands Archaeological Survey (ADIAS): 1992-2006}

The Abu Dhabi Islands Archaeological Survey (ADIAS) was established in 1992 by the late UAE President his highness Sheikh Zayed bin Sultan Al Nahyan, and it continued to operate until 2006. It was charged initially with the archeological survey of Sir Bani Yas, Delma, and Marawah Islands located in the Western Region of Abu Dhabi emirate. Subsequently its remit widened to include the survey of other islands and coastal areas, as well as the desert interior of Abu Dhabi emirate. In 1994 Mark Beech joined the team of archeologists working on Sir Bani Yas Island which discovered a Christian church and monastery there. Further excavation and survey seasons took place annually through the 1990s and early 2000s. It was during some of 
these desert surveys that the ADIAS team began to find late Miocene fossils as well as fossil trackways at a number of locations both along the coast, as well as within the desert interior. One of these sites was located at Ruwais which provided additional rich evidence of proboscideans and birds (Beech and Higgs 2005; Stewart 2005; Stewart and Beech 2006; ADIAS 2006). Important specimens discovered at the Ruwais site included a 2.54 meter long tusk (AUH 1738) of Stegotetrabelodon emiratus. The most important discoveries made by the ADIAS team were a number of impressive trackways made by fossil elephants and other animals at Mleisa and other sites (Higgs et al. 2003, 2005; Higgs 2005). In fact, local people already knew about some of these sites. It was a local oil worker, Mubarak Al-Mansouri, who at the time was working as transport manager at the Jebel Dhanna Terminal for the Abu Dhabi Company for Onshore Oil (ADCO) who first led members of the ADIAS team to the Mleisa 1 trackway site.

In 2000-2001 Beech met with Peter Whybrow, who was still at that time in the Palaeontology Department at the Natural History Museum in London, to show him some of the fossil specimens that had been collected during the ADIAS desert surveys. Whybrow was very encouraging and showed Beech some of the Baynunah material accessioned in the NHM collections. He also shared his original maps used during his Abu Dhabi fieldwork as well as a $\mathrm{CD}$ archive of a website he had been working on concerning the late Miocene fossils from Abu Dhabi. As he was about to retire from the Natural History Museum early in 2002, and as they were no longer interested in hosting the information about the Baynunah Paleontology Project, he entrusted Beech with this archive. The website entitled Miocene Vertebrates from the Emirate of Abu Dhabi, United Arab Emirates was subsequently uploaded to the ADIAS website and still remains to this day (Whybrow and Hill 2006; http://www.adias-uae.com/fossils/index.html). Whybrow retired early in 2002, moving to Cornwall in southwest England. He became a keen 
amateur gardener. Ill-health sadly prevented him from returning to the UAE to take part in the continuing studies of Abu Dhabi's fossils. On 13 February 2004 he died.

The original late Miocene fossils collected from Abu Dhabi's Western Region by the Natural History Museum and Yale University were returned to Abu Dhabi in 2003. It became part of Beech's job at that time to curate the Baynunah fossil collection. A series of cabinets were purchased, and the fossils were organized in taxonomic groups to facilitate access to them. Nigel Larkin, a freelance conservator (formerly a preparator in the Paleontology Department at the NHM) was invited to Abu Dhabi in February 2003 to undertake conservation treatment on some of the important proboscidean specimens collected by ADIAS, such as the 2.54 meter long tusk from Ruwais (AUH 1738). Nigel had previously worked on the Stegotetrabelodon emiratus specimens from Shuwaihat, including the cranium (AUH 502), mandible (AUH 503) and femur (AUH 506).

In November 2005 Hamed Majid Al-Mansouri, a desert ranger, reported to ADIAS the discovery of fossil sites in the Umm Al-Ishtan region. A number of fossil localities were noted including two main areas with fossil tree roots, as well as a third area with proboscidean fossils. Following the receipt of support from the Abu Dhabi Refining Company, TAKREER, a team from ADIAS, including Mark Beech, John Stewart, and Heiko Kallweit, undertook an assessment and excavation of the newly discovered fossil sites at Umm al-Ishtan between 28th January - 2nd February 2006. The main fossil tree root site now has a protective fence around it. No further action was taken on this site. The decision was made, however, to excavate the important proboscidean fossils as they were already partly exposed and likely to suffer further damage with prolonged exposure. Fragments of a proboscidean pelvis, left and right femora, and a tibia were successfully recovered. Appropriate conservation measures were taken to ensure the protection of these important fossil specimens as they were lifted and transported to Abu Dhabi. 
Nigel Larkin was invited to Abu Dhabi in April 2006 (together with Phil Rye) to undertake conservation treatment on the partial proboscidean skeleton discovered by the ADIAS team at Umm Al Ishtan.

The same desert ranger, Hamed Majid Al-Mansouri, also showed the ADIAS team a fossil trackway site located just $2 \mathrm{~km}$ southwest of Bida Al-Mutawaa. This was an arc-shaped exposure of limestone close to a modern goat farm, which had traces of dozens of proboscidean footprints. A series of clear tracks could be seen crisscrossing the outcrop. The size and shape of these appears to be very similar to the two already known proboscidean trackway sites from Mleisa, just south of the Baynunah forest plantation area in the Western Region. A protective fence was subsequently erected around the site to protect it.

During the autumn of 2005 an exhibition on the late Miocene fossils of the region entitled Abu Dhabi 8 million years ago was organized by Beech and Peter Hellyer in the lobby of the headquarters of the former Environmental Research and Wildlife Development Agency - Abu Dhabi (ERWDA, now known as the Environment Agency - Abu Dhabi, EAD). This was inaugurated on 26 November 2005, and a related booklet was published, Abu Dhabi 8 Million Years Ago (Beech and Hellyer 2005; Goodall and Larkin 2005). The exhibition was retained there for around three years, until it was moved in 2009 to the new EAD headquarters at the Mamoura building in Abu Dhabi where the proboscidean material was put on display. This included the Shuwaihat cranium, mandibles, and femur, the Ruwais tusk, and a scale model of Stegotetrabelodon emiratus (Hafeez et al. 2005). These specimens were put on display for nine years until January 2018 when they were returned to the archives of the Department of Culture and Tourism (DCT Abu Dhabi) in preparation for their future display in the forthcoming Zayed National Museum on Saadiyat Island in Abu Dhabi. 


\section{Bibi and the Abu Dhabi Public Works Department: 2003-2006}

In 2003 Faysal Bibi was invited by the then Abu Dhabi Public Works Department to further explore the Baynunah fossil deposits. Two visits were made in that year with small teams, and this resulted in the discovery of new sites and some 200 new fossil specimens. The work principally concentrated on the coastal sites of Shuwaihat, Jebel Barakah, Kihal, Talfaha, and Ras al Qal'a. Important fossils were found, such as additional elephants, much of a giraffe skeleton (AUH 837), and a pelvis (AUH 1134) of a very large ostrich-like bird. Part of this research involved a much more detailed treatment of the Baynunah fossil ratite eggshell than had been carried out before, and this led to the discovery of the ratite Diamantornis laini (Bibi et al. 2006).

Yale University and Abu Dhabi Authority for Culture and Heritage (ADACH): 2006-2012 In 2006 the Abu Dhabi Authority for Culture and Heritage (ADACH) was established. This organization superseded the former Department of Antiquities and Tourism - Al Ain, as well as the former Abu Dhabi Islands Archaeological Survey (ADIAS). Andrew Hill and Faysal Bibi (both at Yale University) were invited back to Abu Dhabi in December 2006 to survey the sites and to help provide recommendations for their future investigation and conservation. This led to the inception in December 2007 of a joint ADACH - Yale University expedition with annual fieldwork. Field seasons then took place in late December 2007 to early January 2008, late December 2008 to early January 2009, late December 2009 to January 2010, and January 2011.

The Yale University team also included Marilyn Fox, David Evans, and Dan Peppe, as well as a number of other international paleontologists and specialists such as Brian Kraatz (Western University, USA), Olga Otero (University of Poitiers, France), Matthieu Schuster (University of Strasbourg, France), Walter Joyce (then at Yale, now at the University of 
Fribourg, Switzerland), Nathan Craig (then at Penn State University, USA), Ali Haidar (American University of Beirut), and Stephen Lokier (then at Abu Dhabi Petroleum Institute, now Bangor University, UK). The ADACH team included local staff such as Mark Beech, Walid Yasin Al-Tikriti, Mohammed Matar Al Dhaheri, Ahmed Abdalla Elhaj Elfaki, Abdulla Khalfan Al Kaabi, Ibrahim Lababidi, Ali Al Meqbali, Abdul Rahman Al Nuaimi, Walid Awad Omar, Hamdan Al Rashedi, Anjana Reddy, and Dia'eddin Tawalbeh. Students from the American University of Beirut, Kareem Zreik and Emil Moacdieh, participated in the 2008-2009 fieldwork, and Aya Attar and Sarwat Majzoub in 2009-2010.

Summaries concerning the importance of Abu Dhabi's late Miocene fossils were included in a number of official Abu Dhabi government reports concerning the state of the environment (Beech et al. 2007, 2009). The results of the paleontological work were also presented at a number of international scientific meetings (Bibi et al. 2008; Fox et al. 2008; Kraatz et al. 2009), as well as subsequently in public lectures (Bibi 2015). Information on the mapping of Abu Dhabi's late Miocene fossils was also provided in the "Environmental Atlas of Abu Dhabi" publication done by the Environment Agency - Abu Dhabi, EAD (Beech 2011). In 2011 work was carried out by the Baynunah Paleontology Project investigating the remarkable elephant trackway site at Mleisa (Craig 2011; Bibi et al. 2012). Kite photography was used to photogrammetrically document the trackway which for the first time provided a clear idea about the site and the interpretation of the behavior of these animals.

The idea for a popular publication with rich illustrations concerning the Baynunah late Miocene fossil discoveries in Abu Dhabi's Western Region had its gestation following a request by the former Chairman of the Abu Dhabi Authority for Culture and Heritage (ADACH), the late Mohammed Khalaf Al Mazrouei. Unfortunately, he died in a car crash in November 2014 before the book could be published. The book took some time to produce due to the number of 
photographs required and the reconstructions of animals (by paleoartist Mauricio Anton), but this eventually resulted in the well-received publication of the volume A Thousand and One FossilsDiscoveries in the Desert at Al Gharbia (Bibi et al. 2017).

\section{Abu Dhabi Tourism and Culture Authority (TCA Abu Dhabi): 2012-2018}

In 2012 the former Abu Dhabi Authority for Culture and Heritage (ADACH) merged with the former Abu Dhabi Tourism Authority (ADTA) to form the Abu Dhabi Tourism and Culture Authority (TCA Abu Dhabi). The Baynunah Paleontology Project was re-established as a collaborative initiative between TCA Abu Dhabi, the Peabody Museum of Natural History, Yale University, USA and the Museum für Naturkunde, Berlin, Germany. It was co-directed by Mark Beech (TCA Abu Dhabi), Faysal Bibi (Berlin Natural History Museum), and Andrew Hill (Peabody Museum of Natural History, Yale University).

Following the detailed screening of deposits from the Shuwaihat fossil site during previous fieldwork seasons, a new species of cane rat was described for the first time in the Baynunah Formation (Kraatz et al. 2013). This was given the name Protohummus dango, in honour of the fact that its teeth resembled chickpeas, 'dango' being the name for a traditional emirati food dish of cooked chickpeas. This was during the time when there were various competing claims throughout the Middle East in the press for who had invented hummus.

The same screening of residues excavated at Shuwaihat revealed an important dental specimen from a monkey. This was a cheek tooth from an ancestor of guenon monkeys which had implications for cercopithecoid biogeography and evolution (Gilbert et al. 2014). Guenon monkeys are today known only from Africa south of the Sahara and are especially diverse in the rain forests of Central and West Africa. At around $7 \mathrm{Ma}$, the Al Gharbia fossil monkey is the oldest guenon monkey known in the world and the first record that guenons ever ranged outside 
of Africa. This gives us a reminder of how different the Arabian climate and environments must have been 7 million years ago.

The Baynunah Paleontology Conference was organized by TCA Abu Dhabi on the $10^{\text {th }}$ December 2014, held at Manarat Al Saadiyat. This was the first public event to bring the latest information about these fossil discoveries to a wider audience. TCA Abu Dhabi invited many of the key paleontologists involved in the Baynunah Project to present at the conference: Mark Beech, Faysal Bibi, Jean-Renaud Boisserie, Marilyn Fox, Brian Kraatz, Ilaria Mazzini, Johannes Müller, Bill Sanders, and Kevin Uno. Following the conference, a field trip was made to visit the Mleisa elephant fossil trackway and the Shuwaihat fossil site. This particular event also provided the visiting paleontologists with an opportunity to examine and study all the fossil specimens previously collected by the Baynunah Paleontology Project. Some of the fruits of this research can now be seen in this volume (Bibi et al. this volume).

On the $12^{\text {th }}$ September 2015 we were very saddened to hear of the death of Andrew Hill. He had been invited to the Baynunah Paleontology Conference in Abu Dhabi but had been too unwell to travel. His contribution to the scientific work on the late Miocene of Abu Dhabi since 1984 was immense, and he is dearly missed. The publication of the book, A Thousand and One Fossils was one of the final things that Andrew worked on, and he was also instrumental in establishing early the vision for this present volume.

\section{Department of Culture and Tourism (DCT Abu Dhabi): 2018 to present}

Today the Historic Environment Department at the Department of Culture and Tourism (DCT Abu Dhabi, formerly known as the Abu Dhabi Tourism and Culture Authority) is responsible for safeguarding all paleontological sites within Abu Dhabi Emirate. In October 2016 a new Cultural Heritage Law of Abu Dhabi was issued by President Sheikh Khalifa bin Zayed Al Nahyan. The 
law governs the mandate of DCT Abu Dhabi to protect, discover, preserve, manage, and promote Abu Dhabi Emirate's heritage.

One of the newest fossil sites to be recently documented was discovered by DCT ranger, Mubarak Al Mazrouei, when patrolling in the Al Dhafra desert. This was the proboscidean trackway site at Bida' al-Ghinia. In December 2017 a team comprising the authors along with Waleed Awad Omar and Ahmed Abdalla Elhaj Elfaki (from DCT) carried out fieldwork documenting several of these known proboscidean trackway sites. This included work at Bida' Al Ghinia, Jebel Mimiyah, and Shahriyya (discovered by Jaber Al-Merri and Ahmed Abdalla Elhaj Elfaki in 2007). The Bida' Al Mutawi'a trackway site was visited and measured by the authors in December 2018 while on a shoot for the US PBS science documentary When Whales Walked: A Deep Time Journey (2019).

The locations of all known late Miocene fossil sites are now stored in DCT's Abu Dhabi Historic Environment Record (ADHER) system. This is a geospatial database that also documents all related reports, publications, and multimedia. The ADHER system also provides a link to the EMu catalogue of all fossil specimens curated by DCT's Collections Department. The Baynunah paleontology database is uploaded within the EMu Collection Management System.

In terms of site protection DCT carries out regular monitoring of the known late Miocene fossil sites, and a number of the most important fossil trackway and fossil sites have now been fenced to ensure their future protection. Economic development and construction activities threaten many areas throughout Abu Dhabi Emirate. Fortunately, all construction activities in Abu Dhabi have to be permitted through the No Objection Certificate (NOC) and Municipal ePermitting System (MePS) which are both digital online applications operated by the Department of Municipalities and Transport (DMT). This means that DCT's Historic Environment Department has the opportunity to review all activities which may endanger known fossil sites. 
Abu Dhabi's Zayed National Museum is still currently under development. There are future plans to display and curate some of the important late Miocene fossils discussed in this publication within this new museum, which is presently under construction on Saadiyat Island in Abu Dhabi. Some of the fossils may also be displayed in a planned natural history museum also being developed on Saadiyat Island.

Abu Dhabi has now become known internationally as one of the key areas in the world for fossils of the Miocene epoch. We have come a long way since petroleum geologists first observed the presence of vertebrate fossils in Abu Dhabi's western Al Dhafra region. This book could not have happened without the international community of scientists who have collaborated over the decades in recovering the lost history of the Baynunah. Today the general public in the United Arab Emirates and elsewhere are far more aware of the importance of fossils and what they can tell us about past environments, extinctions, and climate change. Just as we (Beech, Kraatz, and Bibi) were inspired by Fossil Vertebrates of Arabia, we hope that the next generation of paleontologists and earth scientists - particularly those working in the Middle East - will be inspired by the current work.

\section{References}

ADIAS. (2006). Ruwais. Abu Dhabi Islands Archaeological Survey. http://www.adias-uae.com/ruwais.html. Accessed 11 Oct 2019. Anon. (1975). Mammalian remains from Saudi Arabia, Report on the British Museum (Natural History) 1972-1974. London: Trustees of the British Museum (Natural History).

Beech, M. (2011). Late Miocene Fossil Sites - Ancient Fossils. In Environment Agency - Abu Dhabi, Environmental Atlas of Abu Dhabi (pp. 182-183). Dubai: Motivate Publishing. 
Beech, M., Bibi, F., Sheehan, P., Al-Tikriti, W.Y. \& Yildirim, E. (2009). Cultural Heritage

Resources in Abu Dhabi Emirate. Abu Dhabi: Abu Dhabi Global Environmental Data Initiative (AGEDI) \& Environment Agency - Abu Dhabi (EAD).

Beech, M. \& Hellyer, P. (eds.) (2005). Abu Dhabi 8 Million Years Ago - Late Miocene Fossils from the Western Region. Abu Dhabi: Abu Dhabi Islands Archaeological Survey (ADIAS) \& Dar Al Fajr Printing Press.

Beech, M., Hellyer, P., Gardner, A., Holmes, B. \& Al-Tikriti, W.Y. (2007). Palaeontological and Archaeological Resources in Abu Dhabi Emirate. Abu Dhabi: Abu Dhabi Global Environmental Data Initiative (AGEDI) \& Environment Agency - Abu Dhabi (EAD). Beech, M. \& Higgs, A. (2005). A New Late Miocene Fossil Site in Ruwais, Western Region of Abu Dhabi, United Arab Emirates. In P. Hellyer \& M. Ziolkowski (Eds.), Emirates Heritage Vol. 1 - Proceedings of the 1st Annual Symposium on Recent Palaeontological and Archaeological Discoveries in the Emirates (pp. 6-21). Al Ain: Zayed Centre for Heritage and History.

Bibi, F. (2015). Life on the Baynunah River: Abu Dhabi 7 Million Years Ago. Public lecture given at the New York University Abu Dhabi Institute, 9 September 2015. https://www.youtube.com/watch?v=wnDjQmXXFF0\&t=24s. Accessed 11 Oct 2019.

Bibi, F., Hill, A., Beech, M. \& Yasin, W. (2013). Late Miocene Fossils from the Baynunah Formation, United Arab Emirates: Summary of a Decade of Work. In X. Wang, L.J. Flynn \& M. Fortelius (Eds.), Fossil Mammals of Asia: Neogene Biostratigraphy and Chronology (pp. 583594). New York: Columbia University Press.

Bibi, F., Hill, A. \& Beech, M. (2017). A Thousand and One Fossils-Discoveries in the Desert at Al Gharbia. West Haven: Yale Peabody Museum of Natural History - Yale University Publications in Anthropology \& Abu Dhabi Tourism and Culture Authority. 
Bibi, F., Hill, A., Beech, M. \& Yasin, W. (2008). A river fauna from the Arabian Desert: Late Miocene fossils from the United Arab Emirates. Journal of Vertebrate Paleontology, 28(3), 53A. Bibi, F., Kraatz, B., Craig, N., Beech, M., Schuster, M., \& Hill, A. 2012. Early evidence for complex social structure in Proboscidea from a late Miocene trackway site in the United Arab Emirates. Biology Letters, 8(4), 670-673. doi: rsbl.2011.1185v1-rsbl20111185.

Bibi, F., Kraatz, B., Beech, M., \& Hill, A (Eds.). (this volume). Sands of Time: Late Miocene Fossils from the Baynunah Formation, U.A.E. Cham, Switzerland: Springer.

Bibi, F., Shabel, A.B., Kraatz, B.P. \& Stidham, T.A. (2006). New fossil ratite (Aves:

Palaeognathae) eggshell discoveries from the Late Miocene Baynunah Formation of the United Arab Emirates, Arabian Peninsula. Palaeontologica Electronica, 9 (1), 1-13. https://palaeoelectronica.org/2006_1/eggshell/issue1_06.htm. Accessed 11 Oct 2019.

Boisserie, J.-R., Schuster, M., Beech, M.J., Hill, A. \& Bibi, F. (2017). A new species of hippopotamine (Cetartiodactyla, Hippopotamidae) from the late Miocene Baynunah Formation, Abu Dhabi, United Arab Emirates. PalaeoVertebrata, 41-1-e2. doi: http://dx.doi.org/10.18563/pv.41.1.e2

Boisserie, J-R. \& Bibi, F. (this volume). Hippopotamidae from the Baynunah Formation. In: F. Bibi, B. Kraatz, M. Beech \& A. Hill (Eds), Sands of Time: Late Miocene Fossils from the Baynunah Formation (Pages *******). Cham, Switzerland: Springer.

Craig, N. (2011). Mleisa 1 Kite Orthophoto - GigaPan website. http://gigapan.com/gigapans/78542. Accessed 11 Oct 2019. de Bruijn, H. \& Whybrow, P.J. (1994). A Late Miocene rodent fauna from the Baynunah Formation, Emirate of Abu Dhabi, United Arab Emirates. Proceedings Koninklijke Nederlandse Akademie van Wetenschappen, 97, 407-422. 
Fox, M., Bibi, F. \& Hill, A. (2008). Jacketing the desert sands. Journal of Vertebrate

Paleontology, 28(3), 80A.

Gee, H. (1989). Fossils from the Miocene of Abu Dhabi. Nature, 338, 704.

Gilbert, C.C., Bibi, F., Hill, A., \& Beech, M.J. (2014). Early guenon from the late Miocene

Baynunah Formation, Abu Dhabi, with implications for cercopithecoid biogeography and evolution. Proceedings of the National Academy of Sciences of the United States of America, 111 (28), 10119-10124. doi: https://doi.org/10.1073/pnas.1323888111

Glennie, K.W. \& Evamy, B.D. (1968). Dikaka: plants and plant-root structures associated with aeolian sand. Palaeogeography, Palaeoclimatology, Palaeoecology, 4, 77-87.

Glennie, K.W. (1970). Desert Sedimentary Environments. Amsterdam: Elsevier.

Glennie, K.W. (2005). The Desert of Southeast Arabia: Desert Environments and Sediments. Bahrain: Gulf PetroLink.

Goodall, G. \& Larkin, N. (2005). Appendix 3 - The reconstruction painting “Abu Dhabi 8 million years ago". In M. Beech \& P. Hellyer (Eds.), Abu Dhabi 8 Million Years Ago - Late Miocene Fossils from the Western Region (pp.56-59). ADIAS, Abu Dhabi.

Hafeez, A., Hafeez, I. \& Beech, M. (2005). Appendix 2 - Constructing the scale model of Stegotetrabelodon syrticus". In M. Beech \& P. Hellyer (Eds.), Abu Dhabi 8 Million Years Ago Late Miocene Fossils from the Western Region (pp.43-55). ADIAS, Abu Dhabi.

Higgs, W. (2005). The fossil trackway at Mleisa. In M. Beech \& P. Hellyer (Eds.), Abu Dhabi 8 Million Years Ago - Late Miocene Fossils from the Western Region (pp.37-41). Abu Dhabi Islands Archaeological Survey (ADIAS): Dar Al Fajr Printing Press, Abu Dhabi, UAE. Higgs, W., Gardner, A. \& Beech, M.. (2005). A Fossil Proboscidean Trackway at Mleisa, Western Region of Abu Dhabi, United Arab Emirates. In: P. Hellyer \& M. Ziolkowski (Eds.), Emirates Heritage Vol. 1 - Proceedings of the 1st Annual Symposium on Recent 
Palaeontological and Archaeological Discoveries in the Emirates, Al Ain (pp.21-27). Al Ain:

Zayed Centre for Heritage and History.

Higgs, W., Kirkham, A., Evans, G. \& Hull, D. (2003). A Late Miocene Proboscidean Trackway from Mleisa, United Arab Emirates. Tribulus (Journal of the Emirates Natural History Group), 13(2), 3-8.

Hill, A., Bibi, F., Beech, M. \& Yasin Al Tikriti, W. (2012). Before Archaeology: Life and Environments in the Miocene of Abu Dhabi. In D. Potts \& P. Hellyer (Eds.), Fifty years of Emirates Archaeology (pp.21-33). London: Motivate and the Ministry of Culture, Youth and Community Development.

Hill, A., Whybrow, P.J. \& Yasin Al Tikriti, W. (1990). Late Miocene Primate fauna from the Arabian Peninsular: Abu Dhabi, United Arab Emirates. American Journal of Physical Anthropology, 81, 240-241.

Hill, A., Whybrow, P.J. \& Yasin Al Tikriti, W. (1999). History of Palaeontological Research in the Western Region of the Emirate of Abu Dhabi, United Arab Emirates. In P.J. Whybrow \& A. Hill (Eds.), Fossil Vertebrates of Arabia: With Emphasis on the Late Miocene Faunas, Geology and Palaeoenvironments of the Emirate of Abu Dhabi, United Arab Emirates (pp.15-23). New Haven, CT: Yale University Press.

Kraatz, B., Bibi, F. \& Hill, A. (2009). New rodents from the Late Miocene of the United Arab Emirates. Journal of Vertebrate Paleontology, 29(3), 129A.

Kraatz, B., Bibi, F., Hill, A. \& Beech, M. (2013). A new fossil thryonomyid from the Late Miocene of the United Arab Emirates and the origin of African cane rats. Naturwissenschaften, 100 (5), 437-449. doi: https://doi.org/10.1007/s00114-013-1043-4 
Madden, C.T., Glennie, K.W., Dehm, R., Whitmore, F.C., Schmidt, R.J. Ferfoglia, R.J. \&

Whybrow, P.J. (1982). Stegotetrabelodon (Proboscidea, Gomphotheriidae) from the Miocene of Abu Dhabi. Jiddah: United States Geological Survey.

Stewart, J. (2005). Miocene geology and fossils of Abu Dhabi. In M. Beech \& P. Hellyer (Eds.) Abu Dhabi 8 Million Years Ago - Late Miocene Fossils from the Western Region (pp.14-20). Abu Dhabi: Abu Dhabi Islands Archaeological Survey (ADIAS) \& Dar Al Fajr Printing Press. Stewart, J. \& Beech, M. (2006). The Miocene birds of Abu Dhabi (United Arab Emirates) with a discussion of the age of modern species and genera. Historical Biology, 18(2), 103-113.

Thomas, O. (1894). On some specimens of mammals from Oman. Proceedings of the Zoological Society of London, 448-455.

Thomas, O. (1900). On the mammals obtained in South-western Arabia by Messrs, Percival and Dodson. Proceedings of the Zoological Society of London, 95-104.

Vogt, B., Gockel, W., Hofbauer, H. \& al-Haj, A.A. (1983). The Coastal Survey in the Western Province of Abu Dhabi, 1983. Archaeology in the United Arab Emirates, 5, 49-60.

Wallace, A.R. (1876). The Geographical Distribution of Animals with a study of the Relations of Living and Extinct Faunas as Elucidating the Past Changes of the Earth's Surface. Macmillan and Co., London.

Whybrow, P.J. (1984). Geological and faunal evidence from Arabia for mammal "migrations" between Asia and Africa during the early Miocene. Courier Forschunginstitut Senckenberg, 69, 189-198.

Whybrow, P.J. (1987). Miocene geology and palaeontology of the United Arab Emirates and the State of Qatar (Arabian Gulf): the closure of Tethys and mammal 'migrations' between Afroarabia and Eurasia. M.Phil Thesis, Reading University. 
Whybrow, P.J., Hill, A., Yasin Al-Tikriti, W. \& Hailwood, E. 1990. Late Miocene primate fauna, flora and initial paleomagnetic data from the Emirate of Abu Dhabi, United Arab Emirates. Journal of Human Evolution, 19, 583-588.

Whybrow, P.J. (1989). New stratotype; the Baynunah Formation (Late Miocene). Newsletters on Stratigraphy 21(1): 1-9. doi: https://doi.org/10.1127/nos/21/1989/1

Whybrow, P.J. (Ed.). (2003). Brains in Abu Dhabi's desert. In P.J. Whybrow (Ed.), Travels with the Fossil Hunters. (pp. 75-91). Cambridge: Cambridge University Press in association with the Natural History Museum, London.

Whybrow, P.J. \& Bassiouni, M.A. (1986). The Arabian Miocene: rocks, fossils, primates and problems. In J.G. Else \& P.C. Lee (Eds.)., Primate Evolution (pp.85-91). Cambridge: Cambridge University Press.

Whybrow, P.J. \& Hill, A. (Eds.). (1999). Fossil Vertebrates of Arabia: With Emphasis on the Late Miocene Faunas, Geology and Palaeoenvironments of the Emirate of Abu Dhabi, United Arab Emirates. New Haven, CT: Yale University Press.

Whybrow, P.J. \& Hill, A. (2002). Late Miocene fauna and environments of the Baynunah Formation, Emirate of Abu Dhabi, United Arab Emirates: the Mid-East "Monsoon"? Annales Géologiques des Pays Helléniques, 34(A), 353-362.

Whybrow, P.J. \& Hill, A. (2006). Miocene Vertebrates from the emirate of Abu Dhabi, United Arab Emirates - The Natural History Museum - Yale University Abu Dhabi Miocene Project. Abu Dhabi Islands Archaeological Survey web page. http://www.adias-uae.com/fossils/. Accessed 11 Oct 2019.

Whybrow, P.J., Hill, A., \& Kingston, J.D. (1999). Late Miocene fauna and environments of the Baynunah Formation: Emirate of Abu Dhabi (Western Region), United Arab Emirates. Journal of the Faculty of Science: UAE University, 10(1), 120-145. 
Whybrow, P.J., Hill, A., \& Smith, A.B. (1996). The fossil record. In P. Vine \& I. Al Abed

(Eds.), Natural Emirates: Wildlife and Environments of the United Arab Emirates. (pp.41-50).

London: Trident Press.

Whybrow, P.J., Hill, A., \& Smith, A.B. (1998). Fossils from the UAE's ancient environments. Arabian Wildlife, 3, 42-45.

Whybrow, P.J., Hill, A., \& Smith, A.B. (2005). The fossil record. In P. Hellyer \& S. Aspinall (Eds.), The Emirates: A Natural History (pp.81-89). London: Trident Press.

Whybrow, P.J., Hill, A., \& Al Tikriti, W.Y. (1991). Miocene fossils from Abu Dhabi. Tribulus (Journal of the Emirates Natural History Group), 1(1), 4-9.

Whybrow, P.J., Hill, A., Al Tikriti, W.Y., \& Hailwood, E.A. (1990). Late Miocene primate fauna, flora and initial palaeomagnetic data from the Emirate of Abu Dhabi, United Arab Emirates. Journal of Human Evolution, 19, 583-588. doi: https://doi.org/10.1016/0047$\underline{2484(90) 90066-K}$

Whybrow, P.J. \& McClure, H.A. (1981). Fossil mangrove roots and palaeoenvironments of the Miocene of the eastern Arabian peninsular. Palaeogeography, Palaeoclimatology,

Palaeoecology, 32, 213-225.

Yerbury, J.W. \& Thomas, O. (1895). On the mammals of Aden. Proceedings of the Zoological Society of London, 542-555. 